\title{
Cerebral hyperperfusion syndrome after spontaneous recanalisation of carotid in-stent thrombosis
}

\author{
Pedro Aguilar-Salinas, Michelle S Nunes, Ricardo A Hanel, Mohamad Chmayssani
}

Lyerly Neurosurgery, Baptist Neurological Institute, Jacksonville, Florida, USA

Correspondence to Dr Ricardo A Hanel, rhanel@|yerlyneuro.com

Accepted 8 July 2017

\section{DESCRIPTION}

A 68-year-old man with medical history significant for hypertension and stroke was transferred to our hospital with new onset dysarthria, right face and arm weakness following left carotid stent deployed 24 hours before. The National Institutes of Health Stroke Scale at admission was 7. Head and neck CT angiographies (CTAs) were performed demonstrating in-stent thrombosis of the left carotid artery (figure 1A) and a CT perfusion showed no core infarct but a perfusion defect within the left middle cerebral artery (MCA) territory, as defined by a Tmax greater than $6 \mathrm{~s}$, measuring $78.9 \mathrm{~mL}$ (figure 1B).

Decision was made to treat him conservatively by starting heparin gtt and blood pressure augmentation with norepinephrine for systolic blood pressure goal $>160 \mathrm{~mm} \mathrm{Hg}$. Forty-eighthours after admission, the patient complained of severe headache associated with right-sided paraesthesias and right-sided motor focal seizure without impaired

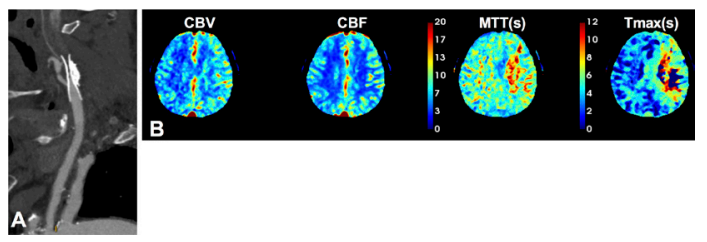

Figure 1 Initial diagnostic images. (A) CT angiography of the neck demonstrating in-stent thrombosis in the left carotid artery and no contrast filling of the internal carotid artery beyond the stent reconstruction. (B) Initial $\mathrm{CT}$ perfusion depicting prolonged time (Tmax) within the territory of the left middle cerebral artery. CBF, cerebral blood flow; CBV, cerebral blood volume; MTT, mean transit time; Tmax, time to peak.

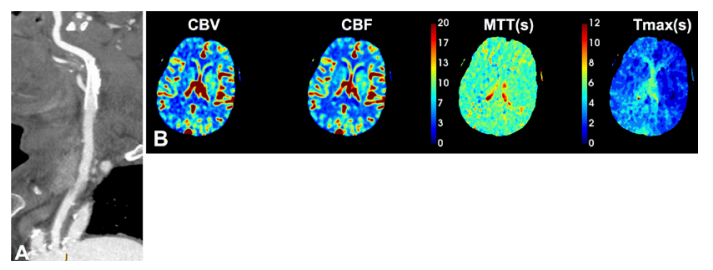

CrossMark

To cite: Aguilar-Salinas $P$, Nunes MS, Hanel RA, et al. BMJ Case Rep Published Online First: [please include Day Month Year]. doi:10.1136/bcr-2017220710

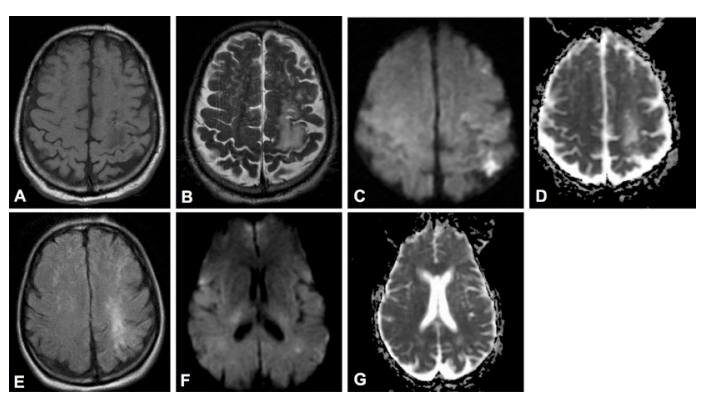

Figure 3 Non-contrast MRI at 48 hours after carotid stent thrombosis demonstrating an old infarction in the watershed area of the left anterior cerebral artery and middle cerebral artery (MCA) in different imaging sequences as well as a new lacunar infarct in the left MCA distribution. (A) T1-weighted sequence showing a small amount of cortical shortening and susceptibility within the medial left precentral gyrus. (B) T2-weighted sequence showing a hyperintense signal in the same anatomical area. (C) Diffusion-weighted imaging (DWI) and (D) apparent diffusion coefficient (ADC) sequences demonstrating restricted diffusion and high signal in the same distribution, respectively. (E) Fluidattenuated inversion recovery sequence demonstrating hyperintensity in the subcortical area in the same vascular distribution. More inferior MRI DWI (F) and ADC (G) slices demonstrating a new lacunar infarct in the territory of the left MCA.

consciousness in the setting of blood pressure nearing $200 \mathrm{~mm} \mathrm{Hg}$. An emergent CT head was performed to rule out haemorrhage. The CTA demonstrated recanalisation of the left carotid artery (figure 2A) and a CT perfusion showed hyperperfusion in the left cerebrum, as defined by increased relative cerebral blood flow (CBF) and relative cerebral blood volume (CBV) along with decreased mean transit time (MTT) and reduced Tmax (figure 2B). Blood pressure was controlled to less than $130 \mathrm{~mm} \mathrm{Hg}$, protamine was given to reverse heparin and the patient was loaded on levetiracetam as a seizure prophylaxis measure. Sudden recanalisation of the carotid artery resulted in an increased and unregulated CBF leading to a cerebral hyperperfusion syndrome (CHS). Subsequent MRI demonstrated the old infarct lesion and new lacunar infarcts in the distribution of the left MCA (figure 3). The patient was stabilised and discharged to a rehabilitation facility. At 90-day clinical follow-up, the patient has a modified Rankin Scale of 4 and he is being taken care at a nursing home.

The CHS is a rare condition that can result after carotid endarterectomy or carotid artery stenting. ${ }^{1}$ Clinical presentation includes acute neurological 
deficits such as new onset headache, seizures, hemiparesis or intracerebral haemorrhage. Early detection of the CHS is paramount to administer an appropriate management and decrease the likelihood of cerebral injury. ${ }^{2}$ CT perfusion has been proposed as a predictive tool for CHS in patients receiving intervention for carotid stenosis, ${ }^{3}$ and it is suitable to provide evidence of hyperperfusion and guide medical treatment.

\section{Learning points}

- Cerebral hyperperfusion syndrome is a rare phenomenon that occurs after a rapid revascularisation of the carotid artery and an unregulated increased of the cerebral blood flow.

- CT perfusion is a suitable imaging tool to provide evidence of cerebral hyperperfusion and guide medical management.

Contributors PA-S and MSN were responsible for study concept and design. MSN contributed to acquisition of the data. All the authors were responsible for analysis and interpretation of the data. PA-S and MSN contributed to drafting of the manuscript. $\mathrm{RH}$ and $\mathrm{MC}$ contributed to critical revision of the manuscript for important intellectual content. All the authors were responsible for administrative, technical and material support. RH and MC contributed to study supervision.

Competing interests RH is a Consultant for Covidien, Stryker, Codman and MicroVention. The other authors have no personal, financial or institutional interest in any of the drugs, materials or devices described in this article.

\section{Patient consent Obtained.}

Provenance and peer review Not commissioned; externally peer reviewed. (C) BMJ Publishing Group Ltd (unless otherwise stated in the text of the article) 2017. All rights reserved. No commercial use is permitted unless otherwise expressly granted.

\section{REFERENCES}

1 Bouri S, Thapar A, Shalhoub J, et al. Hypertension and the post-carotid endarterectomy cerebral hyperperfusion syndrome. Eur J Vasc Endovasc Surg 2011;41:229-37.

2 Faroog MU, Goshgarian C, Min J, et al. Pathophysiology and management of reperfusion injury and hyperperfusion syndrome after carotid endarterectomy and carotid artery stenting. Exp Trans/ Stroke Med 2016;8:7.

3 Chang $\mathrm{CH}$, Chang TY, Chang YJ, et al. The role of perfusion computed tomography in the prediction of cerebral hyperperfusion syndrome. PLoS One 2011;6:e19886.

Copyright 2017 BMJ Publishing Group. All rights reserved. For permission to reuse any of this content visit

http://group.bmj.com/group/rights-licensing/permissions.

BMJ Case Report Fellows may re-use this article for personal use and teaching without any further permission.

Become a Fellow of BMJ Case Reports today and you can:

- Submit as many cases as you like

- Enjoy fast sympathetic peer review and rapid publication of accepted articles

- Access all the published articles

- Re-use any of the published material for personal use and teaching without further permission

For information on Institutional Fellowships contact consortiasales@bmjgroup.com

Visit casereports.bmj.com for more articles like this and to become a Fellow 